\title{
Analysis of MUM1/IRF4 Protein Expression Using Tissue Microarrays and Immunohistochemistry
}

\author{
Yasodha Natkunam, M.D., Ph.D., Roger A. Warnke, M.D., Kelli Montgomery, B.A., \\ Brunangelo Falini, M.D., Matthijs van de Rijn, M.D., Ph.D. \\ Department of Pathology, Stanford University Medical Center, Stanford, California (YN, RAW, KM, MvdR), \\ and Department of Hematology, Perugia University, Italy (BF)
}

The gene encoding MUM1 was characterized as a possible translocation partner in chromosomal abnormalities involving a significant number of multiple myelomas. The overexpression of the MUM1 protein as a result of translocation $t(6 ; 14)(p 25 ; q 32)$ identified MUM1 as a putative regulatory molecule involved in B-cell differentiation and tumorigenesis. The expression of MUM1 protein in multiple myelomas supports this hypothesis. In the current study, using tissue microarray technology, we have tested the expression of the MUM1 protein in 1335 human malignancies and normal tissues. Our data show that the MUM1 protein is expressed in a wide spectrum of hematolymphoid neoplasms and in malignant melanomas but is absent in other human tumors. In addition, in tissue microarrays as well as in conventional paraffin sections, MUM1 staining was found to lack specificity in detecting plasmacytic differentiation as compared with two markers, CD138/Syndecan and VS38, commonly used in paraffin immunohistochemistry for detection of plasma cells.

KEY WORDS: CD138, Immunohistochemistry, IRF4, Lymphoma, Melanoma, Multiple myeloma, MUM1, Plasma cell, Tissue microarray, VS38.

Mod Pathol 2001;14(7):686-694

Chromosomal translocations involving the immunoglobulin heavy-chain (IgH) locus on chromosome 14 (14q32) are detected in $\geq 60 \%$ of cases of multiple myeloma (1-3). Partner chromosome loci and genes participating in these translocations involving the IgH region are largely uncharacterized.

Copyright (C) 2001 by The United States and Canadian Academy of Pathology, Inc.

VOL. 14, NO. 7, P. 686, 2001 Printed in the U.S.A

Date of acceptance: February 28, 2001.

Supported in part by Grant CA34233 from the National Cancer Institute, National Institutes of Health.

Address reprint requests to: Yasodha Natkunam, M.D., Department of Pathology, Stanford University Medical Center, 300 Pasteur Drive, Stanford, CA 94305; e-mail: ynatkunam@yahoo.com; fax: 650-725-7409.
Recent investigations show that deregulation of a novel member of the interferon regulatory factor (IRF) family of genes, MUM1 (multiple myeloma 1)/IRF4 (also known as LSIRF, Pip, and ICSAT), results from the translocation $\mathrm{t}(6 ; 14)$ (p25;q32), juxtaposing this transcription factor to the IgH enhancer locus (4-13). Overexpression of the MUM1 protein resulting from this translocation is detected in multiple myelomas (MM), lymphoplasmacytic lymphomas (LPL), diffuse large B-cell lymphomas (DLBCL), and activated T-cells $(5,7-9,14,15)$. Mice deficient in MUM1 exhibit impaired B- and T-cell function, absence of plasma cells with a drastic reduction in serum immunoglobulins, and an abrogated response to B-cell activation (6). Gene microarray analysis has further shown that the MUM1 gene is preferentially clustered within the gene expression profile exhibited by activated B-like DLBCL, a subset of DLBCL associated with a worse prognosis (16). These studies implicate a significant role for MUM1 in tumorigenesis and immune regulation.

Hematolymphoid neoplasms exhibiting plasmacytic differentiation range from low-grade B-cell lymphomas to multiple myeloma. The recognition of a plasmacytic component in B-cell neoplasia is imperative for classification and assessment of biologic behavior and can be challenging by morphology alone. Thus, markers that reliably detect plasmacytic differentiation are of diagnostic utility. Two such markers, CD138 and VS38, are currently used in paraffin sections. CD138, a member of the syndecan family of integral membrane proteoglycans, is thought to orchestrate cytoadhesive signaling and plays a role in the pathogenesis of multiple myeloma and in the detection of plasmacytic differentiation (17-30). VS38 recognizes a transmembrane protein, $\mathrm{p} 63$, which resides in the rough endoplasmic reticulum and mediates increased secretory function (31-33). Its lack of reactivity for B-cell lymphomas, with the exception of follicular lymphomas and chronic lymphocytic leukemia, 
renders VS38 a useful marker in detecting plasmacytic differentiation (31-35).

The goal of the current study was twofold: to investigate the expression of the MUM1 protein in lymphoid and nonlymphoid human neoplasms and to test its utility in detecting plasmacytic differentiation in lymphomas. To investigate MUM1 protein expression on a large number of human malignancies, we created tissue microarrays containing a variety of hematolymphoid and nonhematolymphoid neoplasms. Paraffin-section immunohistochemistry was employed on the tissue array sections to detect MUM1 protein expression. Staining for CD138 and VS38 was tested in parallel in all hematolymphoid neoplasms. To further define the diagnostic utility of MUM1 in detecting plasmacytic differentiation, we selectively examined additional cases of B-cell lymphomas in which plasmacytic differentiation is conspicuous, including LPL and marginal-zone lymphomas (MZL), using conventional tissue sections of individual cases. MM were not included for detailed study, as the expression pattern of all three markers in MM has been studied previously $(9,14-15,22,25,30,33$, 36-38).

\section{MATERIALS AND METHODS}

\section{Case Selection}

A total of 1335 cases seen at Stanford University Medical Center comprise this study. Hematoxylin and eosin (H\&E)-stained sections, together with immunohistologic studies (if performed at the time of diagnosis) of each case, were reviewed to confirm the original findings. The majority of these cases (1209) were used to create five separate tissue arrays as described below, whereas the remaining 126 cases were studied by conventional H\&E and paraffin-section immunohistochemistry. The lymphoid neoplasms were classified according to the Revised European-American Lymphoma classification system (39). All cases were selected before staining for MUM1, CD138, and VS38.

\section{Tissue Microarrays}

Representative $600-\mu \mathrm{M}$ cores were taken from tissue selected by morphology and immunophenotype as typical of the specific diagnosis. The tissue microarrays were created using a tissue arrayer (Beecher Instruments, Silver Spring, MD) according to a previously described method (40). The first tissue microarray contained 265 hematolymphoid malignancies (lymphoma tissue microarray), as detailed in Table 1. The remaining four tissue microarrays contained normal tissues and nonhematolymphoid malignancies (944 cases) and are summarized in Table 2.

\section{Histologic Features on Conventional Sections}

To examine the histologic and immunophenotypic features of MUM1 protein expression, 126 lymphomas were individually analyzed in detail on H\&E-stained sections. Morphologic parameters, in-

TABLE 1. Tissue Microarray Analysis of MUM1, CD138, and VS38 in Hematolymphoid Neoplasmsa

\begin{tabular}{|c|c|c|c|c|c|c|c|c|c|c|c|c|c|c|c|}
\hline \multirow{2}{*}{ Diagnosis } & \multicolumn{5}{|c|}{ MUM1 } & \multicolumn{5}{|c|}{ CD138 } & \multicolumn{5}{|c|}{ VS38 } \\
\hline & $N$ & $>20 \%$ & $<20 \%$ & 0 & $\%$ Pos & $N$ & $>20 \%$ & $<20 \%$ & 0 & $\%$ Pos & $N$ & $>20 \%$ & $<20 \%$ & 0 & $\%$ Pos \\
\hline A Diffuse large B-cell lymphoma & 70 & 36 & 20 & 14 & 51 & 73 & 1 & 1 & 71 & 27 & 87 & 2 & 26 & 59 & 32 \\
\hline B Follicle center lymphoma & 72 & 11 & 57 & 4 & 17 & 72 & 0 & 2 & 70 & 28 & 72 & 0 & 2 & 70 & 28 \\
\hline C Marginal zone lymphoma & 12 & 7 & 5 & 0 & 58 & 15 & 1 & 0 & 14 & 6 & 15 & 2 & 0 & 13 & 13 \\
\hline D Mantle cell lymphoma & 8 & 2 & 6 & 0 & 33 & 8 & 0 & 1 & 7 & 12 & 7 & 1 & 3 & 3 & 57 \\
\hline E Small lymphocytic lymphoma & 7 & 3 & 4 & 0 & 43 & 7 & 0 & 0 & 7 & 0 & 6 & 0 & 5 & 1 & 83 \\
\hline F Lymphoplasmacytic lymphoma & 2 & 1 & 1 & 0 & 50 & 3 & 0 & 2 & 1 & 66 & 3 & 0 & 2 & 1 & 66 \\
\hline G Multiple myeloma & 2 & 2 & 0 & 0 & 100 & 2 & 1 & 1 & 0 & 100 & 2 & 2 & 0 & 0 & 100 \\
\hline H Posttransplant B-lymphoproliferative disorder & 3 & 2 & 1 & 0 & 67 & 4 & 0 & 1 & 3 & 25 & 4 & 1 & 2 & 1 & 75 \\
\hline I Burkitt's lymphoma & 1 & 0 & 0 & 1 & 0 & 1 & 0 & 0 & 1 & 0 & 1 & 0 & 0 & 1 & 0 \\
\hline J Lymphoblastic lymphoma & 9 & 3 & 3 & 3 & 66 & 9 & 0 & 0 & 9 & 0 & 9 & 0 & 1 & 8 & 11 \\
\hline K Peripheral T-cell lymphoma & 11 & 8 & 3 & 0 & 72 & 11 & 0 & 0 & 11 & 0 & 11 & 0 & 0 & 11 & 0 \\
\hline L Anaplastic large cell lymphoma & 4 & 4 & 0 & 0 & 100 & 4 & 0 & 0 & 4 & 0 & 4 & 0 & 1 & 3 & 25 \\
\hline M Natural killer cell lymphoma & 3 & 1 & 2 & 0 & 33 & 4 & 0 & 0 & 4 & 0 & 4 & 0 & 0 & 4 & 0 \\
\hline $\mathrm{N}$ Systemic mast cell disease & 1 & 0 & 0 & 1 & 0 & 2 & 0 & 0 & 2 & 0 & 2 & 0 & 0 & 2 & 0 \\
\hline O Malignant histiocytosis & 2 & 0 & 1 & 1 & 50 & 2 & 0 & 0 & 2 & 0 & 2 & 0 & 0 & 2 & 0 \\
\hline $\begin{array}{l}\text { P Sinus histiocytosis with massive } \\
\text { lymphadenopathy }\end{array}$ & 3 & 0 & 0 & 3 & 0 & 3 & 0 & 0 & 3 & 0 & 3 & 0 & 0 & 3 & 0 \\
\hline Q Mixed cellularity Hodgkins lymphoma & 1 & 1 & 0 & 0 & 100 & 1 & 0 & 0 & 1 & 0 & 1 & 0 & 0 & 1 & 0 \\
\hline $\begin{array}{l}\text { R Lymphocyte predominance Hodgkins } \\
\text { lymphoma }\end{array}$ & 2 & 2 & 0 & 0 & 100 & 2 & 0 & 0 & 2 & 0 & 2 & 0 & 0 & 2 & 0 \\
\hline Total & 210 & 80 & 103 & 27 & 38 & 223 & 3 & 8 & 212 & 1.3 & 245 & 8 & 50 & 187 & 3 \\
\hline
\end{tabular}

$\mathrm{N}$, number of cases tested (the differences in the numbers of cases tested for each stain vary because of detachment of some tissue cores on slides cut from the tissue array paraffin block.

${ }^{a}$ Immunohistologic staining for MUM1, CD138, and VS38 was scored as follows: $>20 \%=$ moderate to intense staining in $>20 \%$ lesional cells; $<20 \%$ $=$ low-intensity staining in $<20 \%$ lesional; $0=$ no staining in lesional cells; \%Pos (positive) = percentage of all cases with moderate to intense staining in $>20 \%$ lesional cells. 


\begin{tabular}{|c|c|c|c|c|c|}
\hline Tissue/Organ & $N$ & Normal & Benign & Malignant & MUM1 Staining \\
\hline Adrenal & 28 & 9 & 12 & 7 & 0 \\
\hline Appendix & 3 & 2 & 1 & 0 & 0 \\
\hline Bladder & 27 & 1 & 1 & 25 & 0 \\
\hline Breast & 256 & 12 & 17 & $\begin{array}{l}60 \text { In situ carcinoma } \\
167 \text { Invasive carcinoma }\end{array}$ & $\begin{array}{l}0 \\
0\end{array}$ \\
\hline Cartilage & 1 & 1 & 0 & 0 & 0 \\
\hline Cervix & 12 & 1 & 0 & 11 & 0 \\
\hline Colon & 102 & 5 & 7 & 90 & 0 \\
\hline Epididymis & 4 & 4 & 0 & 0 & 0 \\
\hline Esophagus & 17 & 2 & 0 & 15 & 0 \\
\hline Eye & 1 & 1 & 0 & 0 & 0 \\
\hline Gall bladder & 3 & 2 & 0 & 1 & 0 \\
\hline Head \& neck & 31 & 0 & 0 & 31 & 0 \\
\hline Heart & 5 & 3 & 2 & 0 & 0 \\
\hline Kidney & 54 & 8 & 2 & 44 & 0 \\
\hline Liver & 36 & 8 & 9 & 19 & 0 \\
\hline Lung & 64 & 4 & 0 & 60 & 0 \\
\hline Lymph node & 9 & 9 & 0 & 0 & 9 \\
\hline Muscle, skeletal & 9 & 9 & 0 & 0 & 0 \\
\hline Nerve & 3 & 3 & 0 & 0 & 0 \\
\hline Ovary & 37 & 2 & 0 & 35 & 0 \\
\hline Pancreas & 14 & 1 & 1 & 12 & 0 \\
\hline Parathyroid & 8 & 7 & 1 & 0 & 0 \\
\hline Placenta & 2 & 2 & 0 & 0 & 0 \\
\hline Prostate & 47 & 12 & 0 & 35 & 0 \\
\hline Salivary gland & 3 & 3 & 0 & 0 & 0 \\
\hline Skin & 27 & 2 & 1 & $\begin{array}{l}22 \text { Melanoma } \\
1 \text { Basal cell carcinoma } \\
1 \text { Adenocarcinoma }\end{array}$ & $5 / 22$ \\
\hline Small bowel & 6 & 6 & 0 & 0 & 0 \\
\hline Soft tissue & 7 & 7 & 0 & 0 & 0 \\
\hline Spleen & 2 & 2 & 0 & 0 & 0 \\
\hline Stomach & 31 & 4 & 0 & 27 & 0 \\
\hline Testis & 16 & 3 & 0 & 13 & 0 \\
\hline Thymus & 6 & 5 & 1 & 0 & 0 \\
\hline Thyroid & 29 & 9 & 0 & 20 & 0 \\
\hline Uterus & 43 & 4 & 5 & 34 & 0 \\
\hline Vulva & 1 & 0 & 0 & 1 & 0 \\
\hline Total & 944 & 153 & 60 & 731 & $14 / 944$ \\
\hline
\end{tabular}

$\mathrm{N}$, number of cases tested; MUM1 staining, cases in which lesional cells exhibited staining for MUM1.

cluding follicular and diffuse architecture as well as plasmacytic and monocytoid differentiation, were assessed. In MZL, the presence or absence of lymphoepithelial lesions was also evaluated. These cases included 28 LPL, 27 MZL, 50 follicle center lymphoma (FCL), and 21 DLBCL. Of the 27 MZL, 15 involved only lymph nodes and were classified as nodal MZL, whereas the remaining 12 cases involved mucosal sites and were classified as extranodal MZL. The 50 cases of FCL were subclassified as follows: 14 Grade I (predominantly centrocytes), 11 Grade II (centrocytes and centroblasts), and 25 Grade III (predominantly centroblasts). The cases of Grades I and II FCL are discussed together because their clinical behavior is similar to each other and different from that of Grade III FCL (41).

\section{Immunohistochemistry}

Primary antibodies were directed against MUM1 (15), CD138 (Serotec, Oxford, UK), and VS38 (DAKO, Carpinteria, CA). Serial sections of $4 \mu \mathrm{M}$ were cut from the tissue array blocks as well as the conventional paraffin blocks, deparaffinized in xylene, and hydrated in a graded series of alcohol. Heat-induced antigen retrieval was carried out by microwave pretreatment in EDTA ( $1 \mathrm{mM}, \mathrm{pH} 8.0)$ for 15 minutes before staining for MUM1, and in citric acid buffer (10 mM, pH 6.0), for 10 minutes before staining for CD138 and VS38. Detection was carried out using a modified biotin-streptavidinhorseradish peroxidase method (42). To confirm nonspecific staining because of endogenous biotin in tissues such as liver and kidney, sections were incubated with streptavidin horseradish peroxidase followed by diaminobenzidine. The resulting hepatocyte and kidney tubular reactivity was diminished by prior incubation with free avidin followed by free biotin (43). To avoid this problem in liver and kidney of endogenous biotin, an alkaline phosphatase detection system (APAAP) was used in these tissues (44).

The staining for MUM 1 was localized predominantly to the nucleus, although weak to moderate cytoplasmic staining was also present in most cases 
with nuclear positivity. Staining in $>20 \%$ of lesional cells was scored positive, as defined by Tsuboi et al. (14). Staining localized to the plasma membrane was considered positive for CD138, and staining localized to the cytoplasm was considered positive for VS38.

\section{RESULTS}

\section{Expression of MUM1, CD138 and VS38 in Tissue Microarrays}

The results of immunohistologic studies for MUM1, CD138, and VS38 on the lymphoma tissue microarray are summarized in Table 1 and shown in Figures 1 and 2. Staining for CD138 was seen in 3 of 223 cases $(1.3 \%)$, including one DLBCL, one MZL, and one MM. Staining for VS38 was seen in 8
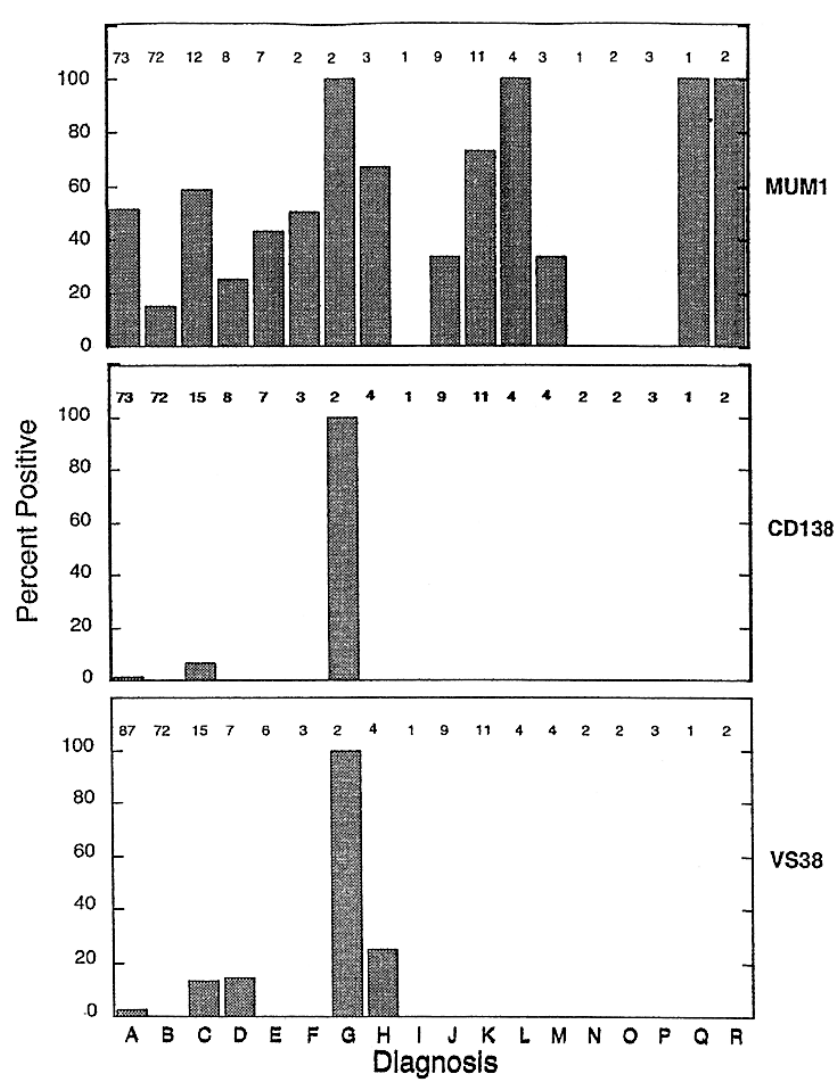

FIGURE 1. Lymphoma tissue microarray results of MUM1, CD138, and VS38 staining depicted graphically show MUM1 staining in a variety of lymphomas, whereas CD138 and VS38 staining shows restricted expression. The lettered labels for each column correspond to the diagnoses listed in Table 1 and are as follows. A, diffuse large B-cell lymphoma; B, follicle center lymphoma; C, marginal-zone lymphoma;

D, mantle cell lymphoma; E, small lymphocytic lymphoma; F, lymphoplasmacytic lymphoma; G, multiple myeloma; H, posttransplant B-lymphoproliferative disorder; I, Burkitt's lymphoma; J, lymphoblastic lymphoma; K, peripheral T-cell lymphoma; $\mathbf{L}$, anaplastic large-cell lymphoma; M, natural killer cell lymphoma; $\mathbf{N}$, systemic mast cell disease; $\mathbf{O}$, malignant histiocytosis; $\mathbf{P}$, sinus histiocytosis with massive lymphadenopathy; Q, mixed-cellularity Hodgkin's lymphoma; R, lymphocyte predominance Hodgkin's lymphoma. The numbers above each column correspond to numbers of cases tested under each category and are also indicated as $N$ in Table 1. of 245 cases (3\%), including two DLBCL, two MZL, one MCL, two MM, and one post-transplant lymphoproliferative disorder (PTLD). In contrast to the relatively restricted staining for CD138 and VS38, staining for MUM1 was detected in 80 of 210 cases (38\%) of lymphoid malignancies, indicating a lack of specificity for plasmacytic differentiation. Of note, $17 \%$ of FCL also showed MUM1 staining (eight of Grade III, two of Grade II, and one of Grade I). On the tissue microarrays of nonhematolymphoid malignancies and nonneoplastic tissues, no MUM1 staining was seen in any of the tissue types tested, with the exception of 5 of 22 melanomas (Table 2 and Fig. 3).

\section{Expression of MUM1, CD138 and VS38 in Conventional Tissue Sections}

The histologic features of the 126 B-cell lymphomas individually analyzed on conventional sections are summarized in Table 3. The cases of LPL were composed of a relatively diffuse proliferation of predominantly small lymphocytes ranging from mature lymphocytes to plasmacytoid lymphocytes to plasma cells. The cases of nodal MZL exhibited prominent monocytoid cells with expansion of the marginal zone. Ten cases showed a vague nodular architecture, although interfollicular and sinusoidal involvement by lymphoma was present. A subset of cases showed a plasmacytic component and follicular colonization. The cases of extranodal MZL showed proliferations of small monocytoid cells and lymphoepithelial lesions with variable degrees of destruction of the epithelium. Four of the 12 extranodal MZL showed areas of plasmacytic differentiation on H\&E-stained sections. The cases of FCL showed nodular architecture, with crowded follicles ranging in cellular composition from predominantly centrocytes to predominantly centroblasts. The cases of DLBCL showed a sheetlike growth pattern composed of atypical large cells with vesicular chromatin and prominent nucleoli. In five cases (two LPL, two extranodal MZL, and one Grade I FCL), probable progression to DLBCL was detected on histologic sections and corroborated by increased staining for the proliferation antigen, Ki-67.

The immunohistologic findings in $126 \mathrm{~B}$-cell lymphomas are summarized in Table 3. Expression of MUM1 protein was detected in all categories of lymphoma, although the number of stained cells was variable, confirming the findings in the tissue microarrays. The staining for MUM1 was moderate to strong and predominantly localized to the nucleus. Weak cytoplasmic staining was seen in a minority of the cells, but no cases showed only cytoplasmic staining in the absence of nuclear staining. In LPL and MZL, MUM1 staining not only 

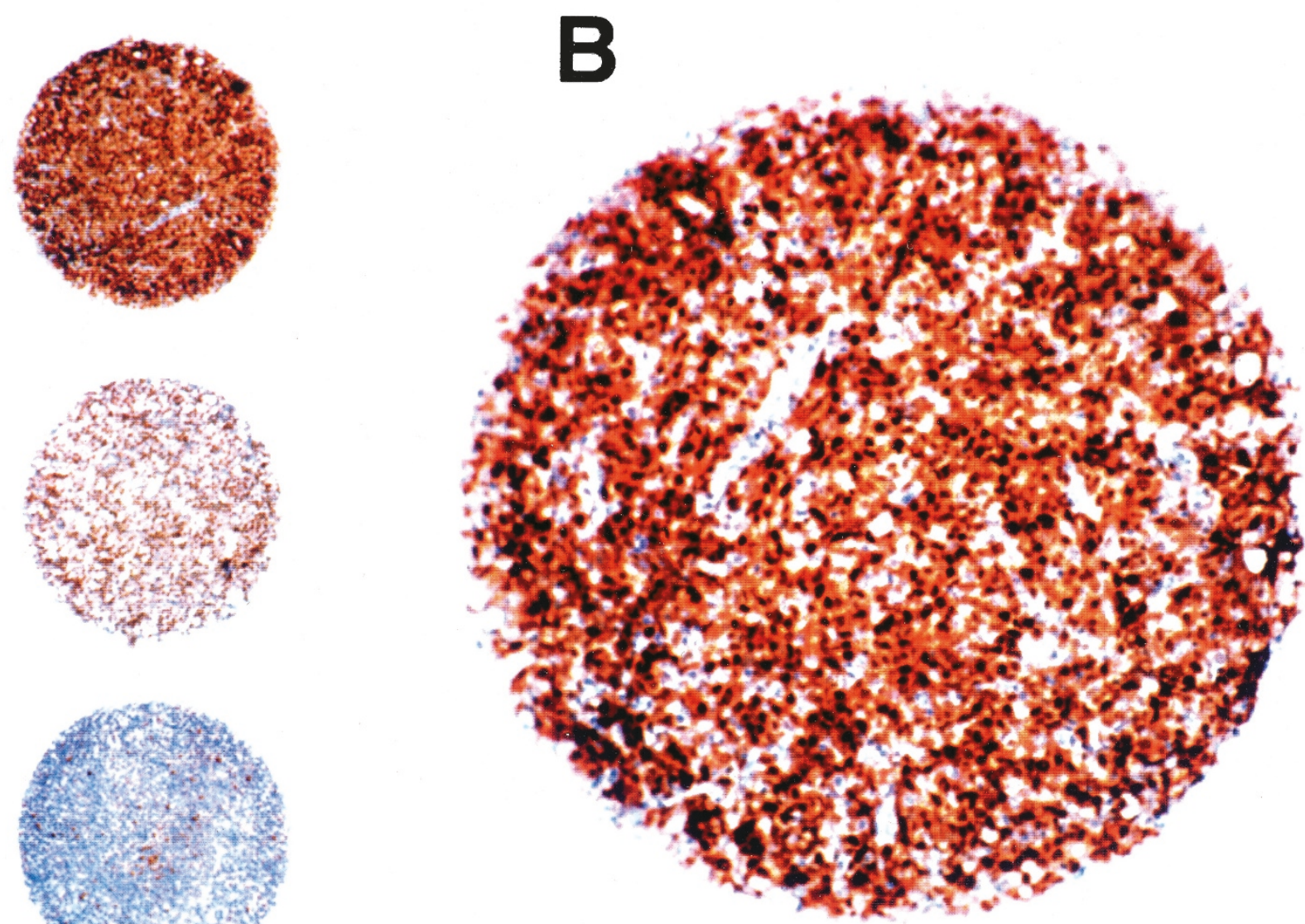

FIGURE 2. Lymphoma tissue microarray stained for MUM1. (A) Examples of strong, weak, and no staining in cases of diffuse large B-cell lymphoma (magnification $\times 20$ ); (B) a core of diffuse large B-cell lymphoma with strong nuclear and weak to moderate cytoplasmic staining for MUM1 (magnification $\times 250$ ).

highlighted areas of plasmacytic differentiation but also detected cells without apparent plasmacytic morphology (as compared with histologic sections).

In DLBCL and FCL, the stained cells did not reveal plasmacytic morphology (Fig. 4), except in a small number of cells $(\sim 1 \%)$, which most likely represent scattered normal plasma cells (positive internal controls). More than $20 \%$ of lesional cells were stained in 15 of 28 (53\%) cases of LPL, closely followed by cases of DLBCL (43\%), MZL, (40\%), and Grade III FCL (40\%). In contrast, only a minority of cases of Grades I and II FCL (8\%) were immunoreactive for MUM1. In the five cases in which progression to DLBCL was detected, MUM1 staining was not increased in areas exhibiting progression and did not correlate with Ki-67 staining. In a subset of cases of FCL (five of Grade I, one of Grade II, and one of Grade III), MUM1 staining showed an unusual geographic pattern. In these cases, 20 to $50 \%$ of the cells comprising the outer edges of the follicle stained for MUM1, whereas only 5 to $10 \%$ of the cells comprising the central portions of the follicles were stained. The MUM1-immunoreactive cells displayed atypical cytologic features (Fig. 5).
Comparative immunohistologic studies for MUM1, CD138, and VS38 are summarized in Table 3 and shown in Figure 6 . The cases of LPL and MZL exhibited variable staining for MUM1, CD138, and VS38. Although all 3 markers stained cells with apparent plasmacytic differentiation, MUM1 also stained cells without plasmacytic differentiation.

\section{DISCUSSION}

The gene encoding MUM1 was characterized as a putative translocation partner in chromosomal abnormalities involving the IgH locus evident in up to $62 \%$ of MM. The overexpression of the MUM1 protein as a result of translocation $t(6 ; 14)$ (p25;q32) identified MUM1 as a potentially significant molecule in the regulation of terminal B-cell differentiation. The expression of MUM1 protein in MM supports this hypothesis. However, prior immunohistochemical studies on small numbers of cases have shown that MUM1 expression is not limited to MM or to plasmacytic cells $(5,7-9,14,15)$. In the current study, using tissue microarrays, we have 


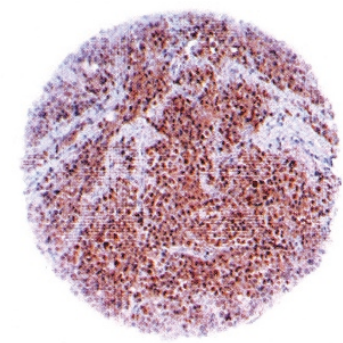

B
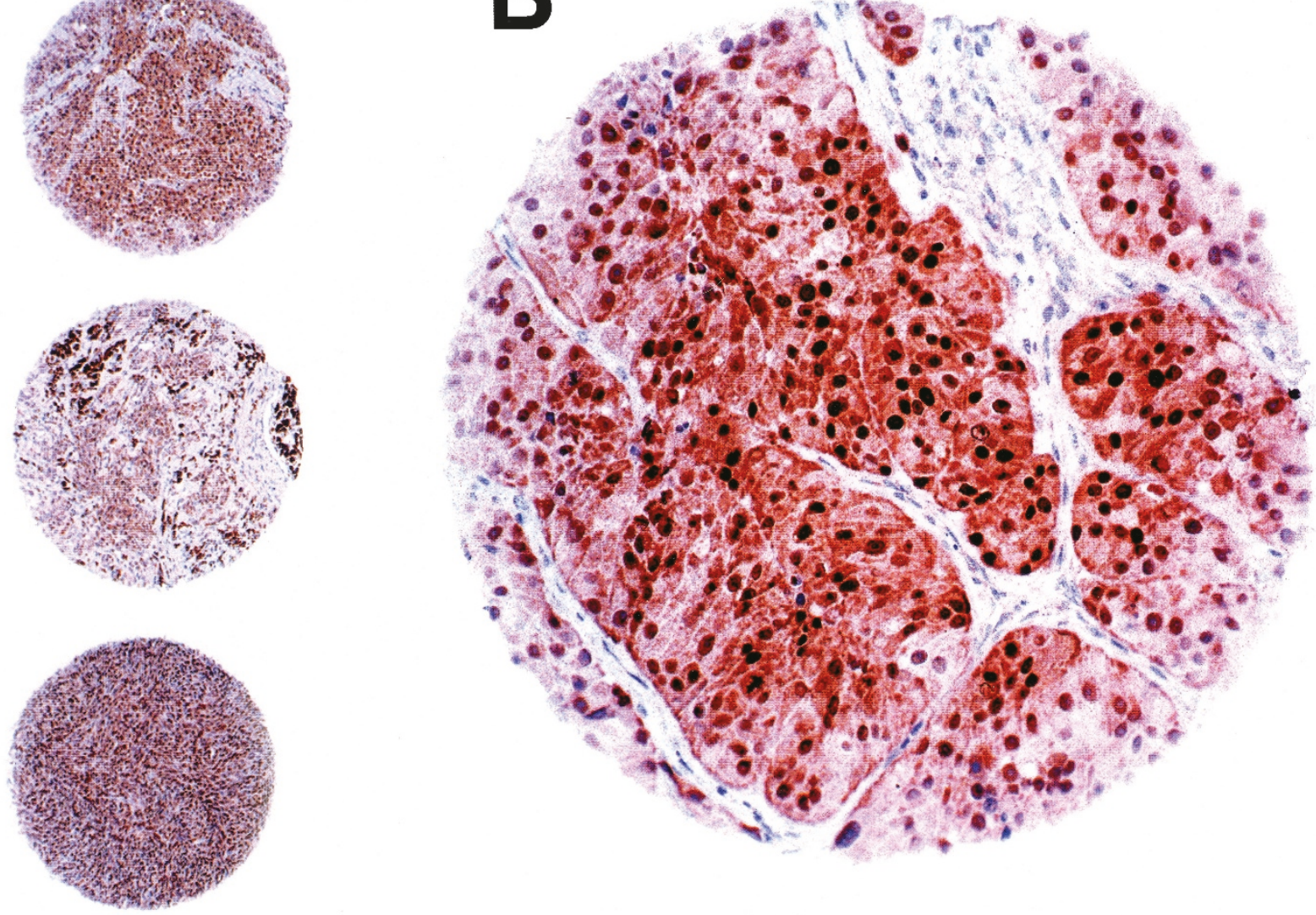

FIGURE 3. Tissue microarray stained for MUM1 highlights strong nuclear and weak to moderate cytoplasmic staining in cores of malignant melanoma (magnification $\times 20$ and $\times 250$ ).

TABLE 3. Summary of Histologic Findings and Comparative Staining for MUM1, CD138, and VS38 on Conventional Paraffin Sections

\begin{tabular}{|c|c|c|c|c|c|c|c|c|c|}
\hline \multirow{2}{*}{ Diagnosis } & \multirow{2}{*}{$N$} & \multicolumn{5}{|c|}{ Histologic Features } & \multicolumn{3}{|c|}{ Immunohistologic Staining } \\
\hline & & FL & DIF & PL & MO & LEL & MUM1 Positive (\%) & CD138 Positive (\%) & VS38 Positive (\%) \\
\hline Lymphoplasmacytic lymphoma & 28 & 0 & 26 & 26 & 0 & 0 & $15 / 28(53)$ & $9 / 28(32)$ & $8 / 26(31)$ \\
\hline Nodal marginal-zone lymphoma & 15 & 10 & 5 & 5 & 15 & 0 & $6 / 15(40)$ & $2 / 15(13)$ & $3 / 13(23)$ \\
\hline Extranodal marginal-zone lymphoma & 12 & 0 & 12 & 4 & 12 & 9 & $5 / 12(42)$ & $3 / 12(25)$ & $0 / 11(0)$ \\
\hline Follicle center lymphoma (I/II) & 25 & 25 & 0 & 0 & 0 & 0 & $2 / 25(8)$ & NT & NT \\
\hline Follicle center lymphoma (III) & 25 & 25 & 0 & 0 & 0 & 0 & $10 / 25(40)$ & NT & NT \\
\hline Diffuse large B-cell lymphoma & 21 & 0 & 21 & 0 & 0 & 0 & $9 / 21(43)$ & NT & NT \\
\hline
\end{tabular}

$\mathrm{N}$, number of cases tested; FL, follicular architecture; DIF, diffuse architecture; PL, plasmacytic differentiation; MO, monocytoid differentiation; LEL, lymphoepithelial lesions; Positive \%, percentage of total number of positive cases (moderate to intense staining in $>20 \%$ lesional cells for MUM1, CD138, and VS38 was designated positive); NT, not tested.

tested the expression of the MUM1 protein in a large number and variety of human malignancies. Our data confirm and expand observations reported in prior studies $(5,7-9,14,15)$ and indicate that the MUM1 protein is expressed in a wide spectrum of hematolymphoid neoplasms and in malignant melanomas but is absent in other human tumors.

Staining for MUM1 was detected in all types of hematolymphoid neoplasms tested in our study with the exception of Burkitt's lymphoma, mast cell, and histiocytic disorders, although only a few cases in these particular categories were tested. A total of $56 \%$ of $\mathrm{T}$ and natural killer (NK)-cell lymphomas stained for MUM1, of which cases of ALCL (100\%) and PTCL (72\%) were the most conspicuous. A total of $35 \%$ of B-cell neoplasms stained for MUM1, with strong staining in MM (100\%), DLBCL (51\%), MZL (58\%), LPL (50\%), PTLDs (67\%), and Hodgkin's disease $(100 \%)$. Our data on tissue microarrays corroborate and extend paraffin immunohistologic findings of MUM1 expression and localization in lymphoid malignancies reported recently (14-15). The slightly lower numbers of MUM1 staining in DLBCL obtained in our study (51\%), compared with that of the prior two papers 


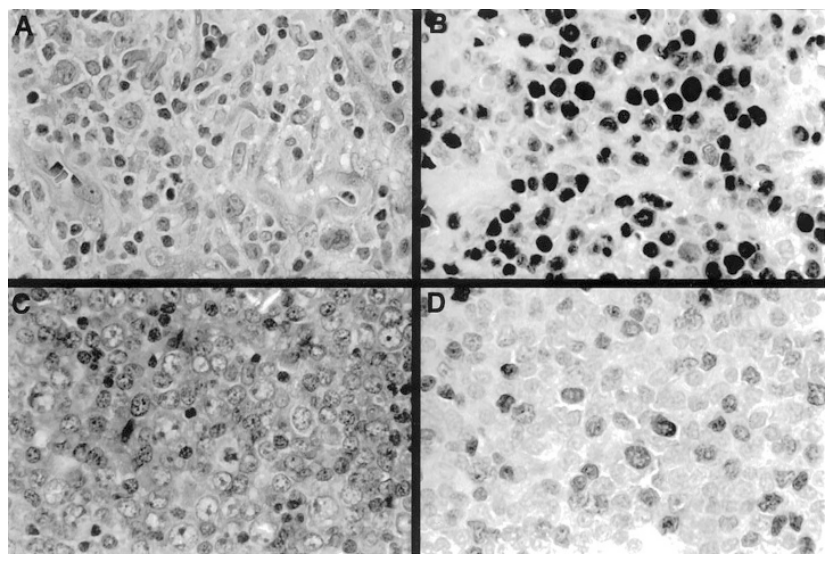

FIGURE 4. Immunohistologic studies for MUM1 on conventional tissue sections of diffuse large B-cell lymphoma (A and $\mathbf{B}$, magnification $\times 250$ ), and follicle center lymphoma, Grade III (C and D, magnification $\times 250$ )

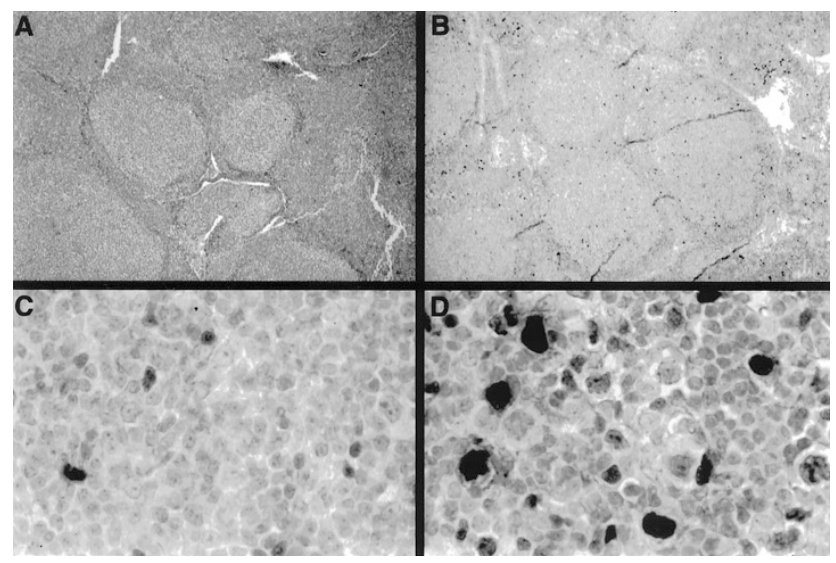

FIGURE 5. Immunohistologic staining for MUM1 on conventional tissue sections of follicle center lymphoma, Grade 1: (A) hematoxylinand eosin-stained section with numerous neoplastic follicles (magnification $\times 20$ ); $(\mathbf{B})$ MUM1 staining is more prominent on the outer edges of the follicles (magnification $\times 20$ ); $(\mathbf{C})$ the center of a follicle shows scattered atypical cells stained for MUM1 (magnification $\times 250$ ); (D) the edge of a follicle shows higher numbers of atypical cells stained for MUM1 (magnification $\times 250$ ).

(73\% and $75 \%)$, are most likely due to differences in case selection and/or sensitivities of immunohistochemical detection systems. As a putative member of the IRF family (4-9), the localization of MUM1 protein to the nucleus is in keeping with a transcriptional role for this molecule. In a subset of cells, weak to moderate cytoplasmic staining was also seen, although cytoplasmic staining alone was not detected in our cases or in those reported by other authors (14-15). A second detection system, APAAP, was used in this study to circumvent the cytoplasmic staining due to endogenous biotin observed in some tissues when stained with a streptavidin-biotin-based detection system.

In normal germinal centers (GC), MUM1 is expressed by $\sim 3$ to $10 \%$ of centrocytes located mainly in the light zone in contact with a meshwork of

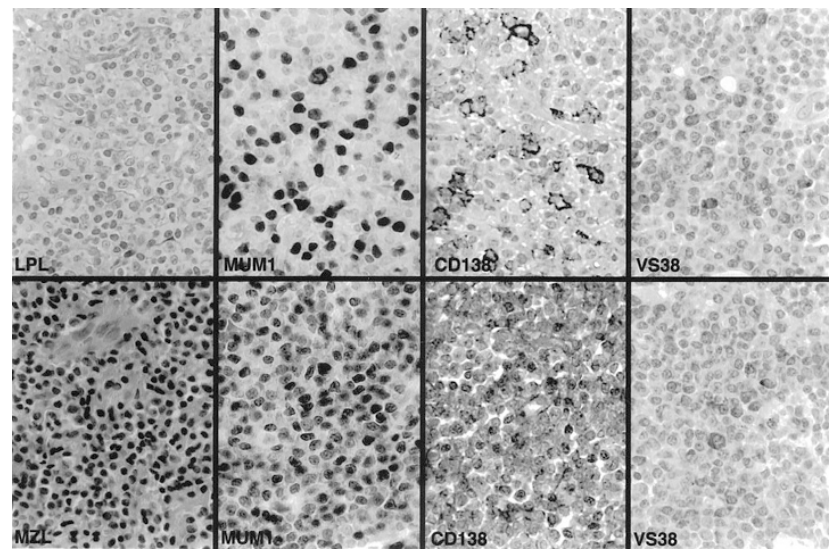

FIGURE 6. Immunohistologic studies for MUM1, CD138, and VS38 on conventional tissue sections of lymphoplasmacytic lymphoma and marginal-zone lymphoma. MUM1 staining is predominantly localized to the nucleus, whereas CD138 staining highlights the cell membranes, and VS38 staining is present within the cytoplasm (magnification $\times 250)$.

follicular dendritic cells (15). MUM1 expression most likely corresponds to activated B cells in this location. This staining pattern is mutually exclusive to that of BCL-6, a marker of GC derivation (15). In addition, in gene microarray analysis, MUM1 segregates with the expression profile of activated B-like DLBCL, a subset of DLBCL associated with a poor outcome (16). Double-labeling immunohistochemistry for BCL-6 and MUM1 show coexpression of the two proteins in $50 \%$ of DLBCL (15). Although MUM1 expression may mark maturing B cells most likely to exit the germinal center, it is yet to be established whether MUM1 expression correlates with B-cell neoplasia of post-GC derivation. Our results on tissue microarrays of MUM1 protein expression show that this protein is widely present in B-cell lymphomas, including those thought to be derived from germinal centers and precursor B-cells. In addition, the expression of the MUM1 protein in T-cell- and NK-cell-derived lymphomas suggests that this protein may play a role in the regulation of a much larger spectrum of lymphoid malignancies than was previously recognized.

In tissue microarrays and in FCL cases analyzed individually by conventional paraffin immunohistochemistry, staining for MUM1 was detected in $23 \%$ of FCL. Falini et al. (15) report MUM1 staining in a subset of FCL, although Tsuboi et al. (14), report absence of staining in all cases of FCL. We have tested a larger number of cases of FCL (122 in total) for expression of the MUM1 protein than reported in these earlier studies (15 cases each; 14-15). Among FCL cases in our study, $79 \%$ of the MUM1-positive cases were Grade III FCL, whereas the remaining $21 \%$ were Grades I and II FCL. Moreover, in a subset of FCL, the MUM1 staining appeared to highlight cells located on the outer edges 
rather than in the center of the follicles. This observation raises the question of whether MUM1 expression indicates either a different stage in maturation or neoplastic transformation of these follicle center B-cells.

The diagnostic utility of MUM1 in paraffin sections in detecting specific types of lymphomas or of the plasmacytic component of B-cell lymphomas was not substantiated in the current study. Under the study conditions we describe, CD138 and VS38 were more effective and specific in detecting plasmacytic differentiation in tissue microarrays as well as in individually tested cases of LPL and MZL. Our findings of the immunoreactivity of CD138 and VS38 in LPL and MZL with and without plasmacytic differentiation are entirely in agreement with previous studies for these markers $(24,25,27,28,45-$ 48). Although careful morphologic correlation of consecutive sections in cases immunoreactive for all three markers revealed similar patterns of distribution of stained cells, MUM1 consistently stained a larger number of lesional cells than did CD138 or VS38. The lesional cells immunoreactive with MUM1 did not necessarily show plasmacytic differentiation, suggesting that MUM1 protein expression may precede the expression of the CD138 and VS38 proteins in B-cell differentiation. Thus, MUM1 may not be a valuable diagnostic tool in the separation of categories of lymphomas or types of differentiation within B-cell lymphomas. It may, however, play an important prognostic role in categories of lymphomas with a worse prognosis, as illustrated in gene microarray profiling (16).

The strong expression of the MUM1 protein in nuclei of a subset of melanomas is of interest. During initial cloning and characterization of the hLSIRF mRNA encoding the MUM1 transcription factor, mRNA expression was noted in a melanoma cell line and in normal melanocytes (8). Our data show that MUM1 is present in a subset of malignant melanomas. More extensive characterization of MUM1 expression in melanomas is underway and will be reported separately.

In summary, our results show that the murine monoclonal antibody directed against the MUM1 protein we used in this study (15) is capable of detecting MUM1 protein expression in a wide variety of B-, T-, and NK-cell lymphomas and in a subset of melanomas. No MUM1 expression was found in a large number of other human malignancies tested. Optimum staining for MUM1 was seen in formalin-fixed sections and was predominantly localized to the nucleus in all immunoreactive cases. Although paraffin-section immunohistochemistry for MUM1 protein expression is amenable to routine diagnostic pathology, its expression pattern in a wide variety of lymphoid malignancies may limit its utility in the differential diagnosis of lymphoid neoplasms. In addition, because MUM1 is expressed in normal germinal centers, it is also not particularly useful as a phenotypic marker of lymphoid neoplasia. However, the expression pattern of MUM1 in lymphomas, together with its cooperative participation with transcription factor PU.1 at the immunoglobulin enhancer locus (1113), suggests that it may have a regulatory role in lymphomagenesis. Further molecular and functional studies are needed, however, to substantiate this consideration.

Acknowledgments: We thank Eva Pfendt and Elizabeth Domanay for technical assistance and Stephen Jaeger for advice on data visualization.

\section{REFERENCES}

1. Bergsagel PL, Chesi M, Nardini E, Brents LA, Kirby SL, Kuehl WM. Promiscuous translocations into immunoglobulin heavy chain switch regions in multiple myeloma. Proc Natl Acad Sci U S A 1996;93:13931-6.

2. Taniwaki M, Nishida K, Takashima T, Nakagawa H, Fujii H, Tamaki T, et al. Nonrandom chromosomal rearrangements of 14q32.3 and 19p13.3 and preferential deletion of $1 \mathrm{p}$ in 21 patients with multiple myeloma and plasma cell leukemia. Blood 1994;84:2283-90.

3. Hallek M, Leif Bergsagel P, Anderson KC. Multiple myeloma: increasing evidence for a multistep transformation process. Blood 1998;91:3-21.

4. Eisenbeis CF, Singh H, Storb U. Pip, a novel IRF family member, is a lymphoid-specific, PU.1-dependent transcriptional activator. Genes Dev 1995;9:1377-87.

5. Matsuyama T, Grossman A, Mittrucker HW, Siderovski DP, Kiefer F, Kawakami T, et al. Molecular cloning of LSIRF, a lymphoid-specific member of the interferon regulatory factor family that binds the interferon- stimulated response element (ISRE). Nucleic Acids Res 1995;23:2127-36.

6. Mittrucker HW, Matsuyama T, Grossman A, Kundig TM, Potter J, Shahinian A, et al. Requirement for the transcription factor LSIRF/IRF4 for mature B and T lymphocyte function. Science 1997;275:540-3.

7. Yamagata T, Nishida J, Tanaka S, Sakai R, Mitani K, Yoshida $\mathrm{M}$, et al. A novel interferon regulatory factor family transcription factor, ICSAT/Pip/LSIRF, that negatively regulates the activity of interferon-regulated genes. Mol Cell Biol 1996;16: 1283-94.

8. Grossman A, Mittrucker HW, Nicholl J, Suzuki A, Chung S, Antonio L, et al. Cloning of human lymphocyte-specific interferon regulatory factor (hLSIRF/hIRF4) and mapping of the gene to 6p23-p25. Genomics 1996;37:229-33.

9. Iida S, Rao PH, Butler M, Corradini P, Boccadoro M, Klein B, et al. Deregulation of MUM1/IRF4 by chromosomal translocation in multiple myeloma. Nat Genet 1997;17:226-30.

10. Glimcher LH, Singh H. Transcription factors in lymphocyte development-T and B cells get together. Cell 1999;96:13-23.

11. Brass AL, Kehrli E, Eisenbeis CF, Storb U, Singh H. Pip, a lymphoid-restricted IRF, contains a regulatory domain that is important for autoinhibition and ternary complex formation with the Ets factor PU.1. Genes Dev 1996;10:2335-47.

12. Perkel JM, Atchison ML. A two-step mechanism for recruitment of Pip by PU.1. J Immunol 1998;160:241-52.

13. Yee AA, Yin P, Siderovski DP, Mak TW, Litchfield DW, Arrowsmith $\mathrm{CH}$. Cooperative interaction between the DNA- 
binding domains of PU.1 and IRF4. J Mol Biol 1998;279: 1075-83.

14. Tsuboi K, Iida S, Inagaki H, Kato M, Hayami Y, Hanamura I, et al. MUM1/IRF4 expression as a frequent event in mature lymphoid malignancies. Leukemia 2000;14:449-56.

15. Falini B, Fizzotti M, Pucciarini A, Bigerna B, Marafioti T, Gambacorta M, et al. A monoclonal antibody (MUM1p) detects expression of the MUM1/IRF4 protein in a subset of germinal center B cells, plasma cells, and activated T cells. Blood 2000;95:2084-92.

16. Alizadeh AA, Eisen MB, Davis RE, Ma C, Lossos IS, Rosenwald A, et al. Distinct types of diffuse large B-cell lymphoma identified by gene expression profiling. Nature 2000;403: 503-11.

17. Iozzo RV. Cell surface heparan sulfate proteoglycan and the neoplastic phenotype. J Cell Biochem 1988;37:61-78.

18. Keating A, Gordon MY. Hierarchical organization of hematopoietic microenvironments: role of proteoglycans. Leukemia 1988;2:766-9.

19. Kjellen L, Lindahl U. Proteoglycans: structures and interactions. Annu Rev Biochem 1991;60:443-75.

20. Carey DJ. Syndecans: multifunctional cell-surface coreceptors. Biochem J 1997;327:1-16.

21. Sutherland AE, Sanderson RD, Mayes M, Seibert M, Calarco PG, Bernfield M, et al. Expression of syndecan, a putative low affinity fibroblast growth factor receptor, in the early mouse embryo.

22. Ridley RC, Xiao H, Hata H, Woodliff J, Epstein J, Sanderson RD. Expression of syndecan regulates human myeloma plasma cell adhesion to type I collagen. Blood 1993;81:76774 .

23. Sanderson RD, Lalor P, Bernfield M. B lymphocytes express and lose syndecan at specific stages of differentiation. Cell Regul 1989;1:27-35.

24. Sebestyen A, Kovalszky I, Mihalik R, Gallai M, Bocsi J, Laszlo $\mathrm{E}$, et al. Expression of syndecan-1 in human B cell chronic lymphocytic leukaemia. Eur J Cancer 1997;33:2273-7.

25. Sebestyen A, Berczi L, Mihalik R, Paku S, Matolcsy A, Kopper L. Syndecan-1 (CD138) expression in human non-Hodgkin lymphomas. Br J Haematol 1999;104:412-9.

26. Carbone A, Gloghini A, Gattei V, Degan M, Improta S, Aldinucci D, et al. Reed-Sternberg cells of classical Hodgkin's disease react with the plasma cell-specific monoclonal antibody B-B4 and express human syndecan-1. Blood 1997;89: 3787-94.

27. Carbone A, Gloghini A, Gaidano G, Franceschi S, Capello D, Drexler HG, et al. Expression status of BCL-6 and syndecan-1 identifies distinct histogenetic subtypes of Hodgkin's disease. Blood 1998;92:2220-8.

28. Carbone A, Gaidano G, Gloghini A, Larocca LM, Capello D, Canzonieri V, et al. Differential expression of BCL-6, CD138/ syndecan-1, and Epstein-Barr virus-encoded latent membrane protein-1 identifies distinct histogenetic subsets of acquired immunodeficiency syndrome-related nonHodgkin's lymphomas. Blood 1998;91:747-55.

29. Witzig TE, Kimlinger T, Stenson M, Therneau T. Syndecan-1 expression on malignant cells from the blood and marrow of patients with plasma cell proliferative disorders and B-cell chronic lymphocytic leukemia. Leuk Lymphoma 1998;31: 167-75.

30. Dhodapkar MV, Abe E, Theus A, Lacy M, Langford JK, Barlogie B, et al. Syndecan-1 is a multifunctional regulator of myeloma pathobiology: control of tumor cell survival, growth, and bone cell differentiation. Blood 1998;91:267988 .
31. Banham AH, Turley H, Pulford K, Gatter K, Mason DY. The plasma cell associated antigen detectable by antibody VS38 is the p63 rough endoplasmic reticulum protein. J Clin Pathol 1997;50:485-9.

32. Gala JL, Chenut F, Hong KB, Rodhain J, Camby P, Philippe $\mathrm{M}$, et al. A panel of antibodies for the immunostaining of Bouin's fixed bone marrow trephine biopsies. J Clin Pathol 1997;50:521-4.

33. Turley H, Jones M, Erber W, Mayne K, de Waele M, Gatter K. VS38: a new monoclonal antibody for detecting plasma cell differentiation in routine sections. J Clin Pathol 1994;47:41822.

34. Sulzbacher I, Fuchs M, Chott A, Lang S. Expression of VS38 in osteoblasts and stroma cells of bone tumors. Pathol Res Pract 1997;193:613-6.

35. Shanks JH, Banerjee SS. VS38 immunostaining in melanocytic lesions. J Clin Pathol 1996;49:205-7.

36. Inki $P$, Larjava $H$, Haapasalmi K, Miettinen HM, Grenman R, Jalkanen M. Expression of syndecan-1 is induced by differentiation and suppressed by malignant transformation of human keratinocytes. Eur J Cell Biol 1994;63:43-51.

37. Gattei V, Godeas C, Degan M, Rossi FM, Aldinucci D, Pinto A. Characterization of anti-CD138 monoclonal antibodies as tools for investigating the molecular polymorphism of syndecan-1 in human lymphoma cells. Br J Haematol 1999; 104:152-62.

38. Al-Janabi K, Cassidy M. Specificity of plasma cell antibody VS38. J Clin Pathol 1996;49:694.

39. Harris NL, Jaffe ES, Stein H, Banks PM, Chan JK, Cleary ML, et al. A revised European-American classification of lymphoid neoplasms: a proposal from the International Lymphoma Study Group. Blood 1994;84:1361-92.

40. Kononen J, Bubendorf L, Kallioniemi A, Barlund M, Schraml $\mathrm{P}$, Leighton S, et al. Tissue microarrays for high-throughput molecular profiling of tumor specimens. Nat Med 1998;4: $844-7$.

41. Bartlett NL, Rizeq M, Dorfman RF, Halpern J, Horning SJ. Follicular large-cell lymphoma: intermediate or low grade? J Clin Oncol 1994;12:1349-57.

42. Bindl JM, Warnke RA. Advantages of detecting monoclonal antibody binding to tissue sections with biotin and avidin reagents in Coplin jars. Am J Clin Pathol 1986;85:490-3.

43. Wood GS, Warnke R. Suppression of endogenous avidinbinding activity in tissues and its relevance to biotin-avidin detection systems. J Histochem Cytochem 1981;29:1196-204.

44. Cordell JL, Falini B, Erber WN, Ghosh AK, Abdulaziz Z, MacDonald S, et al. Immunoenzymatic labeling of monoclonal antibodies using immune complexes of alkaline phosphatase and monoclonal anti-alkaline phosphatase (APAAP complexes). J Histochem Cytochem 1984;32:219-29.

45. Falini B, Bigerna B, Pasqualucci L, Fizzotti M, Martelli MF, Pileri S, et al. Distinctive expression pattern of the BCL-6 protein in nodular lymphocyte predominance Hodgkin's disease. Blood 1996;87:465-71.

46. Dent AL, Doherty TM, Paul WE, Sher A, Staudt LM. BCL-6deficient mice reveal an IL-4-independent, STAT6dependent pathway that controls susceptibility to infection by Leishmania major. J Immunol 1999;163:2098-103.

47. Ye BH, Cattoretti G, Shen Q, Zhang J, Hawe N, de Waard R, et al. The BCL-6 proto-oncogene controls germinal-centre formation and Th2- type inflammation. Nat Genet 1997;16: 161-70.

48. Cattoretti G, Chang CC, Cechova K, Zhang J, Ye BH, Falini B, et al. BCL-6 protein is expressed in germinal-center B cells. Blood 1995;86:45-53. 